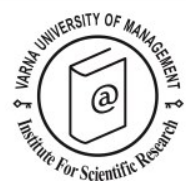

\title{
Roles of place identity distinctiveness and continuity on resident
}

\section{attitude toward tourism}

\author{
Suosheng Wang ${ }^{1 *}$
}

Received: 23/08/2015 Accepted: 21/11/2015

\footnotetext{
1 Indiana University, Indianapolis, USA; phone: 1-(317)-2789098, fax: 1-(317)-2782041; email: suwang@iupui.edu

* Corresponding author
}

\begin{abstract}
Tourism literature pointed out that resident attitude toward tourism is not only affected by what benefits residents can get from tourism development, but also by their place-based identities disregarding the benefits from tourism development. However, few studies have ever empirically explored the nature of the relationships between place identity components and resident attitude toward tourism. This study focuses on discussing the direct and indirect effects of place identity's four components (i.e., place distinctiveness, continuity, self-esteem, and self-efficacy) and resident attitude toward tourism development. One major contribution of this study is that, based on a modified model, this study detects the significant roles of place-based distinctiveness and continuity in predicting resident attitude toward tourism development, which are mainly carried through placebased self-esteem. Significance and implications of this study are discussed.
\end{abstract}

(C) 2016 Varna University of Management. All rights reserved

Keywords: distinctiveness, continuity, place identity, resident attitude, tourism.

Citation: Wang, S (2016) Roles of place identity distinctiveness and continuity on resident attitude toward tourism. European Journal of Tourism Research 13, pp. 58-68

\section{Introduction}

With people's increasing critics on tourism shifting from economic contributions to a locale to preservation of natural environment or local culture, today's tourism planners have to pay more attention than ever to local residents' attitudes toward tourism development. It is believed that, on one hand, local residents' welcome attitude is indispensable to visitors' satisfaction with the destination or their travel experience; on the other hand, only the type of tourism accruing the local's subjective wellbeing will be well accepted by the local people. It is from this perspective that tourism planners must pay special attention to resident's place-based perceptions and their expectations. This reasoning thought is attributed to the fact that tourism is essentially a place-based phenomenon, involving the production of place identity at different scales (Hall 1998). Given its increasing importance, tourism businesses are actively engaged in presenting and promoting place identity, in order to attract tourists and increase market share (Dredge \& Jenkins, 2003). 
Tourism literature stresses the important role of place identity in assessing resident attitude toward tourism development (e.g. Gu \& Ryan, 2008; Palme, Koenig-Lewis \& Jones 2013; Wang \& Xu, 2015). In a study of Beijing's cultural Hutong in China, Gu and Ryan (2008) observed that residents' understanding of a place had more of an impact than the issue of economic gain, and recommended that tourism research should seek to clarify the role of place identity in understanding resident attitudes toward tourism. In the context of placebehaviour studies, Palme, Koenig-Lewis, and Jones (2013) applied the social identity theory to resident's support for tourism, which investigated the relationship between residents' place-based social identity and their tourism involvement and advocacy based on the population comprising the young Welsh adults. Following Palme et al.'s conceptual model, Wang, Zhou, Lee, \& King (2014) investigated the residents of Indiana, USA, which shows that residents' place-based cognitive and affective social identity components have a significant effect on resident attitude toward tourism.

The study of place identity and its application in tourism is complex, whereas the social identity theory is limited by the dominance of 'selfesteem' as the only principle of identity. A more comprehensive study on the application of place identity in tourism should reflect place identity's other important components as well. According to Breakwell (1986), there are four fundamental place-identity components, which should all be considered when explaining place identity and its influence, i.e. place-based distinctiveness, continuity, self-esteem and self-efficacy.

Based on Breakwell's identity process theory, Wang and Xu (2015) developed a conceptual model incorporating the four place identity components, positing direct relationships between the place identity components and resident attitude toward tourism. Their study indicates that there exist direct relationships between place-based self-esteem, self-efficacy, and resident attitude toward tourism. The effects of place-based distinctiveness and continuity, however, were not detected in Wang and Xu's (2015) study. Tourism literature stresses that place identity influences resident attitude toward tourism through distinctiveness, continuity, self-esteem and self-efficacy ( $\mathrm{Gu}$ and Ryan, 2008), yet empirical evidence is still lacking, to prove whether and how place identity distinctiveness and continuity exert their effects on resident attitude toward tourism. This study is designed to fill this gap by examining the relationships between place identity distinctiveness, continuity, and resident attitude toward tourism, and empirically testing the posited relationships.

\section{Conceptual Background}

In place-behaviour studies, Proshansky's (1978) place-identity theory is deemed to be a pioneer in explaining the relationship between place and identity. According to Proshansky, aspects of identity linked to place can be described as place identity. Proshansky's place identity theory provides a theoretical foundation in understanding the relationship between place and identity. In terms of the formation process of place identity, Breakwell (1986) formulates an identity process theory in which identity is seen as a dynamic, social product of the interaction of the capacities for memory, consciousness and organised construal which are guided by different components including distinctiveness, continuity, self-esteem and self-efficacy.

Breakwell (1986) suggested that the first principle of place identity is the establishment of a sense of personal distinctiveness or uniqueness. McGuire (1984) articulated that people in a social context tend to identify with others, with whom they share characteristics that are relatively rare in that context. The distinctiveness motive pushes toward the establishment and maintenance of a sense of differentiation from others (Vignoles, Chryssochoou, \& Breakwell, 2006). The second element of identity is the desire to preserve continuity of the self-concept which focus on the maintenance and development of the continuity. The continuity motive refers to the motivation to maintain a sense of "continuity across time and situation" within identity (Breakwell, 1986, p. 24), which is argued to be a key motive or desire that guides the construction and maintenance of identity (Breakwell, 1986). Place can be used by 
individuals to construct and document their life stories, often via autobiographical memory, because they can act as cues, or memory aids, providing a sense of 'environmental constancy' (Taylor, 2010).

Self-esteem, which is the third element, refers to a positive evaluation of oneself or the group with which one identifies. In terms of place identity, this means that a place's favourite environments can support self-esteem (Korpela, 1989). The self-esteem motive refers to "the motivation to maintain and enhance a positive conception of oneself" (Gecas, 1982, p. 20). The fourth element, self-efficacy is oriented toward maintaining and enhancing feelings of "competence and control" (Breakwell, 1993, p. 205), which is defined as an individual's belief in their capabilities to meet situational demands. Striving for competence has been theorised as a fundamental human motivation (Deci \& Ryan, 2000).

Self-esteem and self-efficacy are considered to be synonymous, yet, the two components vary greatly in meaning. According to Vignoles et al. (2006), participants were happiest about the identity elements that best satisfied motives for self-esteem and efficacy. Self-efficacy differs from self-esteem in that it is a judgment of specific capabilities rather than a general feeling of self-worth (Beck, 2008). For instance, a low-income resident living in a community inhabited mainly by high-income residents may have a low self-efficacy for living a luxurious life like other neighbours, nevertheless, this may not necessarily lead to a negative feeling of self-esteem which is heightened by the impression of the community's overall quality of life. Although efficacy is sometimes portrayed as a component of self-esteem, these constructs are conceptually distinct, and recent research has shown that self-liking and selfcompetence are empirically distinguishable dimensions (Tafarodi \& Swann, 2001).

A great deal of research attests to the importance of "positive distinctiveness" - the belief that one is better than others - in selfesteem maintenance (Wills, 1981). People show more confidence in the accuracy of social comparisons which distinguish them positively from others (Schwartz \& Smith, 1976), and overestimate the uniqueness of their positive attributes (Campbell, 1986). It is considered that a sense of place identity distinctiveness improves one's self-esteem. In other words, a favourable sense of being distinctive can improve one's self-esteem, while a lack of distinctiveness may imply diminishing one's self-esteem; the sense of self-esteem of placeattached residents can be nurtured and improved through the formation of one's favourable perception of the place distinctiveness. For instance, Wasserman, Womersley and Gottlieb (1998) reported that migrants to Chesapeake Bay established strong place attachments and used them to bolster self-esteem via positive distinctiveness. In contrast, the concept of distinctiveness is arguably more relational (and thus social) than the concept of esteem (Schwartz, Luyckx, and Vignoles, 2011), in that one's belonged place is only distinctive in relation to some other place; this is not to deny that esteem can be comparative, but distinctiveness seems to be a more comparative process than esteem. As a whole, it is considered that one's place-based self-esteem is closely associated with his or her sense of place-related distinctiveness.

In addition to distinctiveness's importance in maintaining one's self-esteem, it is considered that a stable sense of place-identity continuity supports and sustains one's self-esteem. Twigger-Ross and Uzzell's (1996) study of attached and non-attached residents of an urban redevelopment site showed evidence of self-in-place continuity and discontinuity respectively via descriptions of place as either consistent or discrepant from self-identity. For the attached residents, according to the study, the place's symbolic traits were used by the residents to achieve their self-esteem. The 'environmental constancy' (continuity) characterised by the place's symbolic traits provides assurance and stability to maintain one's self-esteem, but a disruption or loss of such traits may affect one's self-esteem negatively. According to Gu and Ryan (2008), it is considered that "a degree of stability of selfidentity is arguably important for healthy selfesteem in that a lack of continuity implies a loss of self-esteem, while equally, degrees of permitted change are required for personal development and growth."(p.641). In a sense, it 


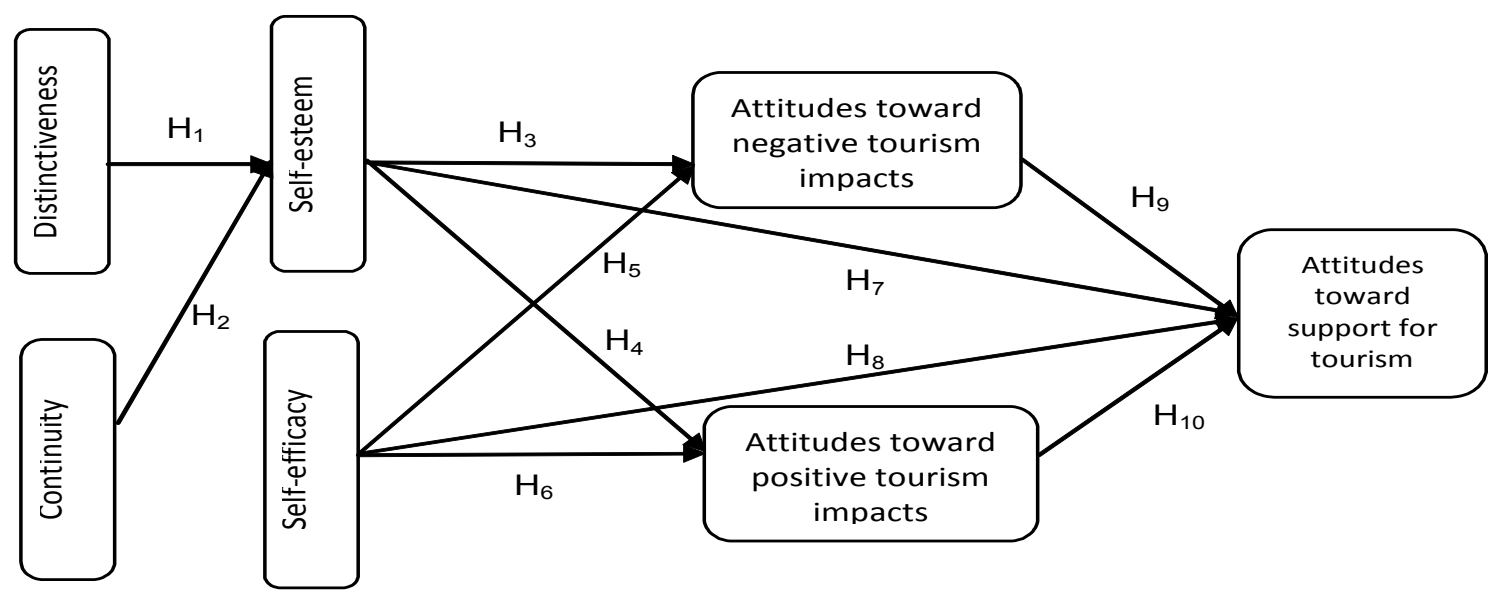

Figure 1. Proposed Model (adapted from Wang \& Xu, 2015)

is considered that one's place-based selfesteem is closely associated with, and can be affected by, one's perceived sense of place identity continuity.

In sum, self-esteem and self-efficacy are considered to be the two major variables contributing to the formulation of resident attitude toward tourism as indicated in Wang and Xu's study (2015). The place-based distinctiveness and continuity may display their influence on resident attitude toward tourism through their close connections with selfesteem. In other words, distinctiveness and continuity should be treated as self-esteem's antecedents when empirically testing their relationships with resident attitude toward tourism. Hence, a modified conceptual model is developed (see Figure 1), in a hope to examine the nature of the relationships between the place identity components and resident attitude toward tourism. As indicated in Figure 1, this model postulates that, while place identity selfesteem and self-efficacy have direct influence on resident attitudes toward negative and positive tourism impacts as well as support for tourism, in contrast, distinctiveness and continuity exert their influence indirectly through self-esteem.

As illustrated in Figure 1, ten hypotheses are constructed for hypothetical testing:

$\mathrm{H}_{1}$ : Residents' place identity distinctiveness has a significant influence on residents' place identity self-esteem;
$\mathrm{H}_{2}$ : Residents' place identity continuity has a significant influence on residents' place identity self-esteem;

$\mathrm{H}_{3}$ : Residents' place identity self-esteem has a significant influence on resident attitudes toward negative tourism impacts;

$\mathrm{H}_{4}$ : Residents' place identity self-esteem has a significant influence on resident attitudes toward positive tourism impacts;

$\mathrm{H}_{5}$ : Residents' place identity self-efficacy has a significant influence on resident attitudes toward negative tourism impacts.

$\mathrm{H}_{6}$ : Residents' place identity self-efficacy has a significant influence on resident attitudes toward positive tourism impacts.

$\mathrm{H}_{7}$ : Residents' place identity self-esteem has a significant influence on resident's behavioral intention to support for tourism.

$\mathrm{H}_{8}$ : Residents' place identity self-efficacy has a significant influence on resident's behavioral intention to support for tourism.

$\mathrm{H}_{9}$ : Resident attitude toward negative tourism impacts has a significant influence on resident's behavioral intention to support for tourism.

$\mathrm{H}_{10 \text { : }}$ Resident attitude toward positive tourism impacts has a significant influence on resident's behavioral intention to support for tourism.

\section{Measures, Sampling and Data Analysis}

To test the hypothetical relations and proposed model, this study adopted the measures used in Wang and Xu (2015) for the constructs of place identity distinctiveness, continuity, self- 
esteem, self-efficacy, negative and positive tourism impacts, and support for tourism. Hence a total of 25 items were adopted and incorporated into the questionnaire.

To test the hypothetical relations, a survey was administered in Indianapolis, a city in the American Mid-west. A city not as popular as some other American cities such as New York or Washington, D. C., in the eyes of international tourists, Indianapolis has made continuous efforts in promoting and developing urban tourism. A decade ago, the Cultural Development Commission in Indianapolis was set up aiming to position the city nationally and globally as an urban tourism destination (Payne 2010). It established the Indianapolis Cultural Tourism Initiative to support and encourage a cultural environment, in an effort to improve the quality of life for Indianapolis residents, and to enhance visitors' experience. One critical challenge facing the city's tourism planners, however, is to identify effective ways to engage the local residents in supporting the urban tourism promotion and development (Wang, Yamada, \& Brothers, 2011).

A self-administered survey was conducted and the convenience sampling technique was employed in data collection. The target subjects were the Indianapolis residents who were at least 18 years old and lived in the city. The data were collected by student research assistants in the city of Indianapolis in April and October, 2014, mainly around the downtown areas where the city residents could be easily intercepted; only those who were local residents and expressed willingness of participation were given the questionnaires. As a result, a total of 464 usable surveys were collected. The respondents' demographic profiles are presented in Table 1.

The data were screened for violations of underlying assumptions by conducting descriptive statistics, using the Statistical Package for the Social Sciences (SPSS 20). Each of the univariate distributions (i.e. distinctiveness, continuity, self-esteem, selfefficacy, negative tourism impact, positive impact, and support for tourism) has skew and kurtosis within reasonable ranges (Skew $<3$, Kurtosis $<10$ ), the values falling well within the guidelines which are regarded to be fairly normal for further structural equation modelling analyses (Kline, 2005). The data were then analysed with LISREL (8.80), a statistical analytic software, used to test the structural model proposed in the study. The goodness of fit indicators used to exhibit a good fit for both the measurement model and structural model were inspected, based on the indices of $x 2 / d f$, $\mathrm{p}$-value, comparative fit index (CFI), normative fit index (NFI) and root mean square error of approximation (RMSEA). The predictor variables' indirect effects were verified based on the Sobel test (Sobel, 1986), aiming to detect if a mediator variable significantly carries the influence of an independent variable to a

Table 1. Respondents' Demographic Profile

\begin{tabular}{|c|c|c|c|c|c|}
\hline Characteristics & $\mathrm{n}$ & $\%$ & Characteristics & $\mathrm{n}$ & $\%$ \\
\hline $\begin{array}{l}\text { Age } \\
18-25\end{array}$ & 164 & 35.4 & $\begin{array}{l}\text { Ethnicity } \\
\text { Hispanic }\end{array}$ & 23 & 5 \\
\hline $26-35$ & 131 & 28.2 & Black, not of Hispanic origin & 55 & 11.9 \\
\hline $36-45$ & 62 & 13.4 & White, not of Hispanic origin & 354 & 76.2 \\
\hline $46-55$ & 67 & 14.5 & Length of residence & & \\
\hline 56 or older & 33 & 7.2 & Less than 3 years & 123 & 26.4 \\
\hline Gender & & & $4-10$ years & 126 & 27.1 \\
\hline Male & 203 & 43.8 & Over 10 years & 215 & 46.4 \\
\hline Female & 259 & 55.8 & About traveling & & \\
\hline Household income & & & $\begin{array}{l}\text { Once a year } \\
2-4 \text { times }\end{array}$ & $\begin{array}{l}59 \\
209\end{array}$ & $\begin{array}{l}12.8 \\
45.1\end{array}$ \\
\hline$<\$ 30,000$ & 119 & 25.7 & More than 4 times & 195 & 42.1 \\
\hline \$30k-60k & 181 & 39.1 & Tourism related jobs & & \\
\hline$\$ 60,001-90 k$ & 94 & 20.3 & yes & 144 & 31 \\
\hline$>\$ 90,000$ & 69 & 14.9 & no & 320 & 69 \\
\hline
\end{tabular}


dependent variable, i.e., whether the indirect effect of the independent variable on the dependent variable through the mediator variable is significant or not.

\section{Results}

Confirmatory Factor Analysis was conducted (see Table 2), to test the fitness of the measurement model. The fit indices were: $x 2$ $(254)=735.54, \mathrm{p}=0.001 ; \mathrm{NFI}=0.92 ; \mathrm{CFI}=$ 0.94; RMSEA $=0.06$, which shows a good fit (MacCallum, Brown, \& Sugawara, 1996). Overall, the measurement model showed a good fit for the data. Convergent validity was assessed by the significant loadings between the observed variables and each latent variable. All the observed variables were loaded at least .65 on their delegated latent variables and were statistically significant $(p<0.01)$. All the AVE values were bigger than the recommended threshold value of .50 (Fornell \& Larcker, 1981), ranging from 0.51 to 0.76, which supported adequate internal consistency. Next, the composite reliabilities of all constructs exceeded the cutoff value of .70 (Hair, Anderson, Tatham, \& Black, 1998), ranging from 0.705 to 0.921 . Thus, the multiple item scales were acceptable in measuring each of the constructs. To compare the AVE with the squared correlations between constructs tested for discriminant validity (Fornell \& Larcker, 1981), the squared correlations between each pair of constructs were all smaller than the AVE values. Thus, discriminant validity was satisfied. Overall, the measurement model showed goodness of fit to the data.

The structural model was estimated to examine the hypothetical relations. The results showed that the goodness-of-fit indices (goodness-of-fit statistics: X2 (262) $=769.23, \mathrm{p}<0.001 ; \mathrm{NFI}=$ 0.91; $\mathrm{CFI}=0.94 ;$ RMSEA $=0.065$ ) were all within the acceptable level, suggesting that the model is adequate. The two place identity components - distinctiveness and continuity explained $51 \%$ of the variation of self-esteem; self-esteem and self-efficacy explained $26 \%$ of the variance in attitudes toward negative impacts, and $23 \%$ of the variance in attitudes toward positive impacts. These variables altogether explained $40 \%$ of the variance in the variable of support for tourism.

Table 3 shows the standardised coefficients and corresponding $t$ values of all the proposed paths. The significant paths include both the Gamma paths (relationships between exogenous constructs and endogenous constructs) and the Eta paths (relationships between endogenous constructs) in the model. The two Gamma paths, from distinctiveness to self-esteem and from continuity to self-esteem, are found to be significant, so are all the eta paths. As displayed in Table 3, all the paths

Table 2. Measure Correlations, the Squared Correlations, and Measurement Properties $(N=$ 432)

\begin{tabular}{|c|c|c|c|c|c|c|c|c|}
\hline \multicolumn{9}{|c|}{ Correlations between Latent Constructs (Squared) } \\
\hline Measures & DIST & CONT & ESTE & EFFI & NEGA & POSI & SUPP & AVE \\
\hline DIST & 1 & & & & & & & 0.51 \\
\hline CONT & $\begin{array}{l}0.42 \\
(0.17)\end{array}$ & 1 & & & & & & 0.74 \\
\hline ESTE & $\begin{array}{l}0.63 \\
(0.39)\end{array}$ & $\begin{array}{l}0.59 \\
(0.34)\end{array}$ & 1 & & & & & 0.52 \\
\hline EFFI & $\begin{array}{l}0.06 \\
(0.03)\end{array}$ & $\begin{array}{l}0.04 \\
(0.01)\end{array}$ & $\begin{array}{l}0.07 \\
(0.04)\end{array}$ & 1 & & & & 0.76 \\
\hline NEGA & $\begin{array}{l}-0.05 \\
(0.02)\end{array}$ & $\begin{array}{l}0.03 \\
(0.00)\end{array}$ & $\begin{array}{l}-0.14 \\
(0.01)\end{array}$ & $\begin{array}{l}0.49 \\
(0.24)\end{array}$ & 1 & & & 0.51 \\
\hline POSI & $\begin{array}{l}0.32 \\
(0.09)\end{array}$ & $\begin{array}{l}0.20 \\
(0.04)\end{array}$ & $\begin{array}{l}0.43 \\
(0.18)\end{array}$ & $\begin{array}{l}-0.20 \\
(0.04)\end{array}$ & $\begin{array}{l}-0.18 \\
(0.03)\end{array}$ & 1 & & 0.52 \\
\hline SUPP & $\begin{array}{l}0.31 \\
(0.09)\end{array}$ & $\begin{array}{l}0.17 \\
(0.28)\end{array}$ & $\begin{array}{l}0.46 \\
(0.21) \\
\end{array}$ & $\begin{array}{l}0.10 \\
(0.01)\end{array}$ & $\begin{array}{l}0.28 \\
(0.07)\end{array}$ & $\begin{array}{l}0.56 \\
(0.31)\end{array}$ & 1 & 0.54 \\
\hline Mean & 3.61 & 3.40 & 3.43 & 3.37 & 2.59 & 3.97 & 3.72 & \\
\hline Cronbach's & 0.705 & 0.840 & 0.710 & 0.766 & 0.791 & 0.849 & 0.921 & \\
\hline
\end{tabular}

Note: DIST = distinctiveness, CONT = continuity, ESTE = self-esteem, EFFI = efficacy, NEGA = negative impact, $\mathrm{POSI}=$ positive impact, SUPP = support for tourism, AVE = average variance extracted. RMSEA = root mean square error of approximation, $\mathrm{CFI}=$ comparative fit index, NFI = normative fit index. Model measurement fit: $x 2=735.54(\mathrm{df}=254, \mathrm{p}<$ $0.001)$, RMSEA $=0.06, \mathrm{CFI}=0.94, \mathrm{NFI}=0.92$. 
indicate positive relationships; in terms of selfefficacy, for instance, a positive relationship between self-efficacy and negative impacts means that a higher sense of self-efficacy may make people feel less sensitive to the negative tourism impacts. With regards to the relations among the place identity elements, significant, positive relations are observed between distinctiveness and self-esteem ( $\beta_{\text {distinctiveness self- }}$ esteem $=0.48, t=7.52)$, and between continuity and self-esteem ( $\beta_{\text {continuity self-esteem }}=0.36, t=$ 6.26). In terms of the relations between perceived place identity senses and tourism impacts, both self-esteem and self-efficacy are found to have significant effects on attitudes to negative tourism impacts ( $\beta_{\text {self-esteem negative-impact }}$ $=0.15, t=2.76 ; \beta_{\text {self-efficacy negative-impact }}=0.50, t=$ $8.74)$, and attitudes to positive tourism impacts $\left(\beta_{\text {self-esteem positive-impact }}=0.43, t=7.07 ; \beta_{\text {self-efficacy }}\right.$ positive-impact $=0.23, \mathrm{t}=4.34$ ), and additionally, self-esteem has a positive impact on support for tourism ( $\beta_{\text {self-esteem tourism-support }}=0.23, \mathrm{t}=$ 3.95). About the relations between perceived tourism impacts and resident's attitude toward support for tourism, both the paths have also shown to be significant ( $\beta_{\text {negative-impact tourism-support }}$ $=0.21, t=3.55 ; \beta_{\text {positive-impact tourism-support }}=0.44, t$ $=7.01)$. As a result, all the hypotheses are accepted except Hypothesis 8, the relationship between self-efficacy and support for tourism.

\section{Discussions}

Indirect Effects of Place-based Distinctiveness and Continuity

This study indicates that residents' place identity sense of distinctiveness is positively associated with self-esteem, so does the sense of continuity with self-esteem. The results reveal that distinctiveness and continuity may have significant influence on resident attitudes via the variable of self-esteem. Self-esteem correlates positively with attitudes to negative impacts and attitudes to positive impacts, which in turn positively influence support for tourism. In other words, a stronger sense of self-esteem may make the residents feel less sensitive to negative tourism impacts, but more responsive to positive tourism impacts, consequently

Table 3. Standardised Maximum Likelihood Parameter Estimates ( $N=432)$

\begin{tabular}{llllll}
\hline Paths & & & $\begin{array}{l}\text { Standardised } \\
\text { Coefficients }\end{array}$ & T Value & $\begin{array}{l}\text { Results of hypothesis } \\
\text { testing }\end{array}$ \\
\hline DIST & $\rightarrow$ & ESTE & 0.48 & 7.52 & $\mathrm{H}_{1}:$ supported \\
CONT & $\rightarrow$ & ESTE & 0.36 & 6.26 & $\mathrm{H}_{2}:$ supported \\
ESTE & $\rightarrow$ & NEGA & 0.15 & 2.76 & $\mathrm{H}_{3}$ : supported \\
ESTE & $\rightarrow$ & POSI & 0.43 & 7.07 & $\mathrm{H}_{4}:$ supported \\
EFFI & $\rightarrow$ & NEGA & 0.50 & 8.74 & $\mathrm{H}_{5}$ : supported \\
EFFI & $\rightarrow$ & POSI & 0.23 & 4.34 & $\mathrm{H}_{6}$ : supported \\
ESTE & $\rightarrow$ & SUPP & 0.23 & 3.95 & $\mathrm{H}_{7}$ : supported \\
EFFI & $\rightarrow$ & SUPP & -0.08 & -1.28 & $\mathrm{H}_{8}$ : Not supported \\
NEGA & $\rightarrow$ & SUPP & 0.21 & 3.55 & $\mathrm{H}_{9}$ : supported \\
POSI & $\rightarrow$ & SUPP & 0.44 & 7.01 & $\mathrm{H}_{10}$ : supported \\
\hline NOSE
\end{tabular}

Note: DIST = distinctiveness, CONT = continuity, ESTE = self-esteem, EFFI = efficacy, NEGA = negative impact, $\mathrm{POSI}=$ positive impact, SUPP = support for tourism, AVE $=$ average variance extracted. RMSEA $=$ root mean square error of approximation, $\mathrm{CFI}=$ comparative fit index, NFI = normative fit index. Goodness-of-fit statistics: $x 2=769.23$ (df $=262, p$ $<0.001)$, RMSEA $=0.065, \mathrm{CFI}=0.94, \mathrm{NFI}=0.91$

Table 4. Results of Indirect-effect Tests

\begin{tabular}{|c|c|c|c|c|c|c|}
\hline \multicolumn{5}{|c|}{ Independent V. $\rightarrow$ Mediator V. $\rightarrow$ Dependent V. } & \multirow{2}{*}{$\begin{array}{l}\text { Sobel test statistics } \\
2.809\end{array}$} & \multirow{2}{*}{$\begin{array}{l}\text { Two-tailed P-value } \\
0.0050\end{array}$} \\
\hline DIST & $\rightarrow$ & ESTE & $\rightarrow$ & NEGA & & \\
\hline CONT & $\rightarrow$ & ESTE & $\rightarrow$ & NEGA & 2.683 & 0.0073 \\
\hline DIST & $\rightarrow$ & ESTE & $\rightarrow$ & POSI & 5.338 & 0.0001 \\
\hline CONT & $\rightarrow$ & ESTE & $\rightarrow$ & POSI & 4.601 & 0.0001 \\
\hline DIST & $\rightarrow$ & ESTE & $\rightarrow$ & SUPP & 5.471 & 0.0001 \\
\hline CONT & $\rightarrow$ & ESTE & $\rightarrow$ & SUPP & 4.685 & 0.0001 \\
\hline ESTE & $\rightarrow$ & NEGA & $\rightarrow$ & SUPP & 2.278 & 0.0227 \\
\hline EFFI & $\rightarrow$ & NEGA & $\rightarrow$ & SUPP & 3.227 & 0.0013 \\
\hline ESTE & $\rightarrow$ & POSI & $\rightarrow$ & SUPP & 5.126 & 0.0001 \\
\hline EFFI & $\rightarrow$ & POSI & $\rightarrow$ & SUPP & 5.505 & 0.0001 \\
\hline
\end{tabular}

Note: DIST $=$ distinctiveness, CONT = continuity, ESTE $=$ self-esteem, EFFI = efficacy, NEGA = negative impact, $\mathrm{POSI}=$ positive impact, SUPP = support for tourism 
generating a stronger behavioural intention to support for tourism. Likewise, the associations between self-efficacy and the other constructs follow the same pattern. For instance, when residents feel more confident in self-efficacy, they tend to rate attitudes to positive impacts more favourably, hence holding a stronger sense of behavioural intention to support for tourism; on the other hand, a stronger sense of self-efficacy may make people feel less sensitive to the negative impacts caused by tourism.

The Sobel test was employed to examine the significance of the mediating effects of selfesteem, attitudes to negative impacts, and attitudes to positive impacts. As shown in Table 4 , all the mediator variables exercised significant effects: self-esteem mediated the relations between distinctiveness and attitudes to negative impacts and between distinctiveness and attitudes to positive impacts, and intervened the relations between continuity and attitudes to negative impacts and between continuity and attitudes to positive impacts; attitudes to positive impacts and attitudes to negative impacts mediated the associations between self-esteem and support for tourism, and between self-efficacy and support for tourism, respectively.

This study shows that place-based distinctiveness and continuity can influence resident attitude toward tourism impacts indirectly through the mediator variable of self- esteem. Moreover, as indicated by the results of the Sobel test, resident attitudes toward tourism impacts, both negative and positive, play significant roles in governing the relationships between residents' senses of selfesteem, self-efficacy, and their behavioural intentions to support for tourism. This study hitherto displays all the significant influence made by place identity components on resident attitude toward tourism impacts and resident's behavioural intentions to support for tourism, therefore, the modified model successfully captures all the components' significant effects and explicitly illustrates the interactive relations of the place identity components in terms of their influence on resident attitude toward tourism.

\section{The Modified Model versus the Original Model}

A separate structural equation modelling analysis was conducted to examine how Wang and Xu's (2015) model might fit into this study's dataset. The results show that only self-esteem and self-efficacy were found to be significant in contributing to resident attitude toward tourism, no direct relations were noted for place identity distinctiveness and continuity. In contrast, the difference of the $x^{2}$ values (i.e., $x_{\text {diff }-v a l u e)}^{2}$ between the modified model and Wang and Xu's model is $769.23-759.95=9.28$, and the difference of the degrees of freedom is 262 $255=7$, which verifies that the $x_{\text {diff }}^{2}-$ value is insignificant and the modified model is a parsimonious model, proving the modified model better fits into the dataset. In addition,

Table 5. Comparisons of Significant Effects on Resident Attitude toward Tourism

\begin{tabular}{|c|c|c|c|}
\hline $\begin{array}{l}\text { Significant effects shown in the } \\
\text { Modified Model }\end{array}$ & Variance explained & $\begin{array}{l}\text { Significant effects shown in } \\
\text { Wang \& Xu's (2015) Model }\end{array}$ & Variance explained \\
\hline $\begin{array}{l}\mathrm{DIST} \rightarrow \mathrm{ESTE} \rightarrow \mathrm{NEGA} \\
\mathrm{CONT} \rightarrow \mathrm{ESTE} \rightarrow \mathrm{NEGA} \\
\mathrm{ESTE} \rightarrow \mathrm{NEGA} \\
\mathrm{EFFI} \rightarrow \mathrm{NEGA}\end{array}$ & $\begin{array}{l}26 \% \text { in 'negative } \\
\text { impacts' }\end{array}$ & $\begin{array}{l}\mathrm{ESTE} \rightarrow \mathrm{NEGA} \\
\mathrm{EFFI} \rightarrow \mathrm{NEGA}\end{array}$ & $\begin{array}{l}29 \% \text { in 'negative } \\
\text { impacts' }\end{array}$ \\
\hline $\begin{array}{l}\mathrm{DIST} \rightarrow \mathrm{ESTE} \rightarrow \mathrm{POSI} \\
\mathrm{CONT} \rightarrow \mathrm{ESTE} \rightarrow \mathrm{POSI} \\
\mathrm{ESTE} \rightarrow \mathrm{POSI} \\
\mathrm{EFFI} \rightarrow \mathrm{POSI}\end{array}$ & $\begin{array}{l}23 \% \text { in 'positive } \\
\text { impacts' }\end{array}$ & $\begin{array}{l}\mathrm{ESTE} \rightarrow \mathrm{POSI} \\
\mathrm{EFFI} \rightarrow \mathrm{POSI}\end{array}$ & $\begin{array}{l}24 \% \text { in 'positive } \\
\text { impacts' }\end{array}$ \\
\hline $\begin{array}{l}\mathrm{DIST} \rightarrow \mathrm{ESTE} \rightarrow \mathrm{SUPP} \\
\mathrm{CONT} \rightarrow \mathrm{ESTE} \rightarrow \mathrm{SUPP} \\
\mathrm{ESTE} \rightarrow \mathrm{SUPP} \\
\mathrm{ESTE} \rightarrow \mathrm{NEGA} \rightarrow \text { SUPP } \\
\mathrm{ESTE} \rightarrow \mathrm{POSI} \rightarrow \text { SUPP } \\
\mathrm{EFFI} \rightarrow \mathrm{NEGA} \rightarrow \text { SUPP } \\
\mathrm{EFFI} \rightarrow \mathrm{POSI} \rightarrow \text { SUPP }\end{array}$ & $\begin{array}{l}40 \% \text { in 'support for } \\
\text { tourism' }\end{array}$ & $\begin{array}{l}\mathrm{ESTE} \rightarrow \mathrm{SUPP} \\
\mathrm{ESTE} \rightarrow \mathrm{NEGA} \rightarrow \text { SUPP } \\
\mathrm{ESTE} \rightarrow \mathrm{POSI} \rightarrow \text { SUPP } \\
\mathrm{EFFI} \rightarrow \mathrm{NEGA} \rightarrow \text { SUPP } \\
\mathrm{EFFI} \rightarrow \mathrm{POSI} \rightarrow \text { SUPP }\end{array}$ & $\begin{array}{l}41 \% \text { in 'support for } \\
\text { tourism' }\end{array}$ \\
\hline
\end{tabular}

Note: DIST $=$ distinctiveness, CONT $=$ continuity, ESTE $=$ self-esteem, EFFI = efficacy, NEGA = negative impact, POSI = positive impact, SUPP = support for tourism 
based on the literature review, the modified model is considered to be of more logical rationale. It is considered that the modified model is a more comprehensive and meaningful model in capturing and displaying the relationships between the place identity components and resident attitude toward tourism.

Illustrated on Table 5 are the effects of place identity components on resident attitude toward negative tourism impacts, positive tourism impacts and behavioural intentions toward support for tourism, generated from through the modified model and Wang and Xu's (2015) model for comparisons. The results show a consistent pattern with regards to the effects of self-esteem and self-efficacy. The discrepancy is that, for the modified model, both distinctiveness and continuity display significant indirect effects on resident attitude toward negative impacts, positive impacts, and support for tourism, through the mediator variable of self-esteem. As indicated by the explained variances on Table 5, the modified model better demonstrated the relationships between the place identity elements and resident attitude toward tourism.

\section{Conclusion}

Contributions of this study are both academic and practical. Theoretically, this study explores the relationships of place identity components and resident attitude toward tourism, and explains how place identity components may work together to influence resident attitude toward tourism. All the four place-identity components - distinctiveness, continuity, selfesteem, and self-efficacy - are identified to be significant predictors based on the modified model. While echoing the findings in Wang and $\mathrm{Xu}$ (2015) that self-esteem and self-efficacy directly influence resident attitude toward the impacts of tourism development, this study further identifies the significant roles of distinctiveness and continuity in the formation of resident attitude toward tourism. Empirical evidence shows that the effects of distinctiveness and continuity on resident attitude toward tourism are mainly carried through the mediator variable of self-esteem. Notably, distinctiveness and continuity explain over half of the variance of self-esteem, indicating that the residents' place-based selfesteem is largely dependent on their senses distinctiveness and continuity. The distinctiveness theory argues that identities that distinguish people from others will be selected (Mehra, Kilduff, \& Brass, 1998), implying that one is better than the others; with regards to continuity, a place's stable symbolic traits provides assurance and stability to maintain one's self-esteem. This study affirms that distinctiveness and continuity are two fundamental components which may directly affect one's sense of self-esteem, which, in turn, influences one's attitude and behavioural intentions.

Practically, the findings of this study highlight the importance of fostering a city's place identity and emphasize the importance of a place's uniqueness and continuous features to maintain the attractiveness of the place and local residents' civic pride. Successful tourist cities across the world make no attempt to alter their place identities, and have always maintained the original styles and landscapes even when renovating streets or districts. The place identity not only helps maintain the residents' civic pride and sense of belonging, but also continues to attract millions of tourists who are interested in experiencing the identities. On the contrary, a city may become less attractive when its long place identity alters. For the last couple of decades, many Chinese cities witnessed drastic changes with many old streets and ancient-styled buildings replaced by 'modern' ones, which can even hardly be recognised or lauded by the local residents. From the tourism perspective, such reconstructions make many Chinese cities lose their original lustre, and even make the residents feel alienated with the city due to the missing or confusing place identity. The example here illustrates the importance of maintaining and nurturing place identity on the course of local tourism development or city renovation. As for the city of Indianapolis, which strives to build up its image by renovating the six cultural districts, the tourism policy makers and developers should hence apply the place identity principles of distinctiveness, continuity, self-esteem and self-efficacy in the process of cultural districts renovation; only when the residents feel 
consolidated with their perceived place identity will they become more likely to support the city's tourism development.

In short, this study proposed a modified structural model to depict the relationships among the place-identity components as well as their associations with resident attitude toward tourism. Place-based self-esteem and self-efficacy proved to lay significant influence on resident attitude toward tourism, and distinctiveness and continuity were verified to be self-esteem's significant antecedents. Compared with Wang and Xu's (2015) model, the modified model successfully captures the effects of all the place-identity components, which proved to be more comprehensive and better explain the relationships of the place identity components, resident attitude toward negative tourism impacts and positive tourism impacts, and resident's behavioural intention to support for tourism. In terms of limitations of this study, the survey data utilised in the current study were collected with a non-random convenience sampling approach, hence possible sampling errors could occur, and results may not exempt from possible bias. It is recommended that future studies in this field should consider adopting a random sampling approach, which would make the sample more representative of the city population.

\section{References}

Beck, M. (2008). If at First You Don't Succeed, You're in Excellent Company. The Wall Street Journal, April 29, p. D1.

Breakwell, G. (1986). Coping with Threatened Identities. London: Methuen.

Campbell, J. D. (1986). Similarity and uniqueness: The effects of attribute type, relevance, and individual differences in self-esteem and depression. Journal of Personality and Social Psychology, 50, 281-294.

Deci, E. L., \& Ryan, R. M. (2000). The "what" and "why" of goal pursuits: Human needs and the self-determination of behavior. Psychological Inquiry, 11, 227-268.

Dredge, D. \& Jenkins J. (2003). Destination place identity and regional tourism policy. Tourism Geographies, 5(4), November, 383-407.
Fornell, C., \& Larcker, D. F. (1981). Evaluating structural equation models with unobservable variables and measurement error. Journal of Marketing Research, 18, 39-50.

Gecas, V. (1982). The self-concept. Annual Review of Sociology, 8, 1-33.

Gu, H., \& Ryan, C. (2008). Place attachment, identity and community impacts of tourism - the case of a Beijing Hutong. Tourism Management, 29, 637-647.

Hair, J.F. Jr., Anderson, R.E., Tatham, R.L., \& Black, W.C. (1998). Multivariate Data Analysis, (5 $5^{\text {th }}$ Edition). Upper Saddle River, NJ: Prentice Hall.

Hall, C. M. (1998). Introduction to Tourism: Development, dimensions and issues. Melbourne: Longman.

Kline, R. B. (2005). Components and practice of structural equation modeling (2nd ed.). New York: Guilford Press.

Korpela, K. M. (1989). Place identity as a product of environmental self-regulation. Journal of Environmental Psychology, 9, 241-256.

MacCallum, R. C., Brown, M. W., \& Sugawara, H., M. (1996). Power Analysis and Determination of Sample Size for Covariance Structure Modeling. Psychological Methods, 1(2): 130-49.

McGuire, W. J. (1984). Search for the self: Going beyond self-esteem and the reactive self. In R. A. Zucker, J. Aronoff, \& A. I. Rabin (Eds.), Personality and the prediction of behavior, 73-120, New York: Academic Press.

Mehra, A., Kilduff, M., \& Brass, D. J. (1998). At the Margins: A Distinctiveness Approach to the Social Identity and Social Networks of Underrepresented Groups. The Academy of Management Journal, 1(4), 441-452.

Palme A., Koenig-Lewis N., \& Jones L. E. M (2013). The effects of residents' social identity and involvement on their advocacy of incoming tourism. Tourism Management, 38, 142-151.

Payne, B. (2010), Indianapolis Cultural Trail, Where will our next big idea come from? Retrieved on July 26, 2010, from: http://indyculturaltrail.org/blog/.

Pizam, A., Uriely, N., \& Reichel, A. (2000). The intensity of tourist-host social relationship 
and its effects on satisfaction and change of attitudes: the case of working tourists in Israel. Tourism Management, 21(4), 395-406.

Proshansky, H. (1978). The self and the city. Environment and Behavior, 10(2), 147169.

Schwartz, J. M., \& Smith, W. P. (1976). Social comparison and the inference of ability difference. Journal of Personality and Social Psychology, 34, 1268-1275.

Schwartz, S. J., Luyckx, K., and Vignoles V. (2011). Handbook of Identity Theory and Research. Springer New York Dordrecht Heidelberg London. Retrieved from: books.google.com/books?isbn=14419798 83.

Sedikides, C., \& Strube, M. J. (1995). The multiply motivated self. Personality and Social Psychology Bulletin, 21, 1330-133.

Sobel, M. E. (1986). Some New Results on Indirect Effects and Their Standard Errors in Covariance Structure. Sociological Methodology, 16, 159-186.

Tafarodi, R. W., \& Swann, W. B., Jr. (2001). Two-dimensional self-esteem: Theory and measurement. Personality and Individual Differences, 31, 653-673.

Taylor, S. (2010). Narratives of identity and place. London: Routledge.

Twigger-Ross, C. L., \& Uzzell, D. L. (1996). Place and identity processes. Journal of Environmental Psychology, 16(3), 205220.
Vignoles, V. L., Regalia, C., Manzi, C., Golledge, J., \& Scabini, E. (2006). Beyond Self-esteem: Influence of Multiple Motives on Identity Construction. Journal of Personality and Social Psychology, 90(2), pp.308-333.

Wang, S., \& Xu, H. (2015). Influence of Placebased Senses of Distinctiveness, Continuity, Self-esteem and Self-efficacy on Resident Attitudes toward Tourism. Tourism Management, 47, 241-250.

Wang, S., Yamada, N., \& Brothers, L. (2011). Discussion of Factors and Challenges for Urban Cultural Tourism Development. International Journal of Tourism Research, 13, 553-569.

Wang, S., Zhou, L., Lee, S., \& King, C. (2014). Analysis of Residents' Social Identity, Tourism Engagement and Propensity for Tourism Advocacy, Advances in Hospitality and Leisure, 10 (111-131).

Wasserman, D., Womersley, M., \& Gottlieb, S. (1998). Can a sense of place be preserved? In A. Light \& J. M. Smith (Eds.), Philosophy and geography III: Philosophies of place, (pp. 191-213). Lanham, MD: Rowman \& Littlefield.

Williams, J., \& Lawson, R. (2001). Community Issues and Resident Opinions of Tourism. Annals of Tourism Research, 28 (2), 269290.

Wills, T. A. (1981). Downward comparison components in social psychology. Psychological Bulletins, 90, 245-271. 